\title{
Prevalence of Hypertrophic Cardiomyopathy in Fetuses of Mothers with Gestational Diabetes before Initiating Treatment
}

\section{Prevalência de miocardiopatia hipertrófica em fetos de mães com diabetes gestacional antes do tratamento}

\author{
Carolina Rossi Palmieri ${ }^{1} \quad$ Mona Adalgisa Simões $^{2}$ Jean Carl Silva ${ }^{3}$ Anelise Darabas dos Santos ${ }^{4}$ \\ Mariana Ribeiro e Silva ${ }^{4}$ Bruna Ferreira ${ }^{4}$
}

${ }^{1}$ Health and Environment Master Program, Universidade da Região de Joinville (Univille), Joinville, Santa Catarina, Brazil

2 Department of Neonatology, Maternidade Darcy Vargas, Joinville,

Santa Catarina, Brazil

${ }^{3}$ Department of Medicine, Universidade da Região de Joinville

(Univille), Joinville, Santa Catarina, Brazil

${ }^{4}$ Universidade da Região de Joinville (Univille), Joinville, Santa

Catarina, Brazil

Address for correspondence Carolina Rossi Palmieri, Programa de Pós-graduação em Saúde e Meio Ambiente, Universidade da Região de Joinville (Univille), Rua Blumenau, 26, bairro América, Joinville/SC, CEP 89204-248, Brazil (e-mail: dracarolrossi@gmail.com).

Rev Bras Ginecol Obstet 2017;39:9-13.
Abstract
Keywords
- gestational diabetes
- fetal echocardiography
- fetus
- heart diseases
- hypertrophic cardiomyopathy

Objective To evaluate the prevalence of hypertrophic cardiomyopathy (HCM) in fetuses of pregnant women with gestational diabetes mellitus (GDM) in the beginning of the treatment.

Methods A cross-sectional study was performed between July 1, 2013, and December 20, 2013, in a public maternity clinic in southern Brazil. The subjects were 63 fetuses of mothers with gestational diabetes, with a single pregnancy and no other associated pathologies. We diagnosed HCM through a fetal echocardiography before treatment and evaluated the maternal and fetal characteristics.

Results The average age of the pregnant women was $32.32( \pm 6.2)$ years, and the average gestational age at the time of the evaluation was $30.59( \pm 2.27)$ weeks. The interventricular septum thickness showed a standard deviation of more than two in $50.8 \%$ of the fetuses (95\% confidence interval [95\% Cl]: 38.1-63.5\%). The left ventricular wall thickness showed a standard deviation of more than 2 in 13 (20.6\%) fetuses (95\%Cl: $11.1-30.2 \%)$. The HCM was confirmed in $54 \%$ of the fetuses ( $95 \% \mathrm{Cl}: 41.3-65.1 \%)$. The fetal abdominal circumference was normal in 46 (73\%) fetuses, and $50 \%$ of these fetuses had HCM.

Conclusion The prevalence of hypertrophic cardiomyopathy in fetuses of pregnant women with GDM before treatment was of $54 \%$ (95\% Cl: $41.3-65.1 \%)$. received

July 5, 2016

accepted

December 15, 2016
DOI http://dx.doi.org/

10.1055/s-0037-1598602. ISSN 0100-7203.
Copyright $\odot 2017$ by Thieme-Revinter

Publicações Ltda, Rio de Janeiro, Brazil
License terms

(c) $(1) \$$ 


\begin{abstract}
Resumo
Palavras chave

- diabetes gestacional

- ecocardiografia fetal

- feto

- cardiopatias

- miocardiopatia hipertrófica

Objetivo Avaliar a prevalência de miocardiopatia hipertrófica em fetos de gestantes com diabetes mellitus gestacional antes do início do tratamento.

Métodos Foi realizado um estudo de corte transversal, no período de $1^{\circ}$ de julho de 2013 até 20 de dezembro de 2013, em uma maternidade pública. Foram objetos do estudo 63 fetos de gestantes portadoras de diabetes mellitus gestacional (DMG), em gestação única e sem outras patologias associadas. Foi realizada ecocardiografia fetal antes do início do tratamento do diabetes. O diagnóstico de miocardiopatia hipertrófica $(\mathrm{MH})$ foi realizado quando a medida do septo interventricular ou da parede ventricular estava superior a dois desvios-padrão. O desfecho primário avaliado foi presença de $\mathrm{MH}$.

Resultados As gestantes apresentavam idade média de $32,32( \pm 6,2)$ anos, e a idade gestacional média no momento da avaliação foi de $30,59( \pm 2,27)$ semanas. A medida do septo interventricular estava acima de 2 desvios-padrão em $50,8 \%$ (intervalo de confiança de $95 \%$ [IC95\%]: 38,1-63,5\%). A parede do ventrículo esquerdo estava acima de 2 desvios-padrão em 13 fetos, totalizando 20,6\% (IC95\%: 11,1-30,2\%). A MH estava presente em 54\% dos fetos (IC95\%: 41,3-65,1\%). A circunferência abdominal fetal estava normal em 46 (73\%) fetos, e destes, 50\% apresentavam $\mathrm{MH}$.

Conclusão A prevalência de $\mathrm{MH}$ em fetos de gestantes portadoras de DMG antes do tratamento foi de 54\% (IC95\% 41,3-65,1\%).
\end{abstract}

\section{Introduction}

Gestational diabetes mellitus (GDM) is defined as glucose intolerance with onset or diagnosis during pregnancy. It affects $\sim 7 \%$ of all pregnancies, resulting in over 200 thousand cases per year. ${ }^{1}$

Previous studies have shown that maternal hyperglycemia may lead to fetal hypertrophic cardiomyopathy $(\mathrm{HCM})^{2}$ and cardiac diastolic function impairment, ${ }^{3}$ among other alterations.

Hypertrophic cardiomyopathy is characterized by an increased ventricular wall thickness, which leads to a decrease in the left ventricular cavity size, to a potential reduction in the ventricular systolic performance, and to the impairment of the diastolic function because of the decreased ventricular filling. These alterations can lead to heart failure and death. ${ }^{4}$

Cardiac complications due to congenital heart malformation and ventricular hypertrophy are the major causes of morbidity and mortality in fetuses and newborns of mothers with GDM. ${ }^{5}$

The incidence of HCM, especially interventricular septal hypertrophy (IVSH), varies between $10 \%$ and $71 \%{ }^{6-8}$ An increase in the ventricular wall thickness may also be involved in the cardiac changes observed in fetuses of mothers with GDM, but septal hypertrophy is more studied because of the higher number of insulin receptors in the septum of the heart. ${ }^{9}$

Prenatal HCM is diagnosed through intrauterine two-dimensional echocardiography, and, based on the results, physicians may provide appropriate postnatal care and follow-up for cardiac hypertrophy progression during the gestational period. ${ }^{10}$ Some authors claim that fetal echocardiography should be recommended to all pregnant women with GDM. ${ }^{11}$

The aim of the present study was to assess the prevalence of HCM in fetuses of pregnant women with GDM before their treatment using fetal echocardiography.

\section{Methods}

The present cross-sectional study included 63 fetuses of mothers with GDM, and was conducted before the mothers initiated their treatment in a public maternity clinic at the southern region of Brazil between July 12013 and December 202013.

The study was conducted according to the local regulations for good clinical practices, specifically those of the resolution of the Brazilian National Health Council (CNS, in the Portuguese acronym, resolution no. 466/12), after approval from the Research Ethics Committee (CEP011/12) of the institution. The principal researcher and collaborators were responsible for providing information to the patients. None of the authors were associated with the companies that provided the equipment or their competitors, and did not receive any kind of support.

The study included singleton fetuses of pregnant women diagnosed with GDM, without malformations and other diseases that could interfere with the fetal development. The diagnosis of GDM was based on the criteria provided by the American Diabetes Association, that is, blood glucose level $\geq 92 \mathrm{mg} / \mathrm{dl}$ (fasting), $\geq 180 \mathrm{mg} / \mathrm{dl}$ (1 hour after plasma glucose) and $\geq 153 \mathrm{mg} / \mathrm{dl}$ ( 2 hours after plasma glucose), and an ultrasound was performed between the 24th and 
28th gestational weeks. Fetuses diagnosed with malformations after their inclusion in the study were then excluded.

The fetal abdominal circumference (FAC) was determined as the average of three measurements obtained at the stomach, umbilical vein, and liver levels. The FAC percentile for the gestational age was calculated according to the method reported by Hadlock et al. ${ }^{12}$ Interventricular septum and left ventricular wall thickness were determined through fetal Doppler echocardiography using two-dimensional sequential analysis for a longitudinal transverse section at the left atrioventricular (bicuspid) valve tip level using the Mmode. ${ }^{13}$ The test was performed before the patients initiated the treatment for GDM. ${ }^{14}$ Septum and/or left ventricular wall thickness values showing a standard deviation of more than 2 according to the gestational age were considered abnormal, that is, consistent with the findings of HCM. ${ }^{15-17}$ The fetal echocardiographs were obtained by the same technician using the HD 7XE (Philips ${ }^{\circledR}$, Amsterdam, Netherlands) equipment.

The maternal data assessed were age, parity, pre-pregnancy body mass index $\left(\mathrm{BMI}=\mathrm{W} / \mathrm{H}^{2}\right)$, and gestational age at the time of inclusion in the study. The fetal data assessed were FAC percentile and interventricular septum and left ventricular wall thickness. The primary and secondary outcomes assessed were the presence of HCM and FAC respectively.

All variables were descriptively analyzed, with quantitative variables expressed as means and standard deviations.

Data were statistically analyzed using the Statistical Package for the Social Sciences (SPSS, IBM-SPSS, Inc., Chicago, IL, EUA) software, version 21.0. Continuous (quantitative) variables were expressed as means and standard deviations. Categorical (qualitative) variables were expressed as absolute and relative frequencies. The $95 \%$ confidence interval (95\%CI) for the frequency was calculated using the one-sample $t$-test.

\section{Results}

Sixty-three pairs (pregnant woman and her fetus) were selected, and none was excluded. The average age of the pregnant women was $32.32( \pm 6.2)$ years, and the average gestational age at the time of the evaluation was $30.59( \pm 2.27)$ weeks. The majority of the pregnant women had multiple gestations (66.66\%), and a pre-pregnancy BMI $>25 \mathrm{~kg} / \mathrm{m}^{2}$ (65.07\%); the average BMI was $27.33( \pm 5.64) \mathrm{kg} / \mathrm{m}^{2}$. Maternal data are shown in - Table $\mathbf{1}$.

The interventricular septum thickness showed a standard deviation of more than 2 in $50.8 \%$ of the fetuses, between 1 and 2 in $38.09 \%$ of the fetuses, and less than one in $11.11 \%$ of the fetuses (95\%Cl: 38.1-63.5\%). The left ventricular wall thickness showed a standard deviation of more than 2 in 13 fetuses (20.6\%) (95\%CI: $11.1-30.2 \%)$, and HCM was confirmed in $54 \%$ of the fetuses (95\%Cl: $41.3-65.1 \%)$. Only 2 (5.88\%) of the 34 fetuses with HCM exhibited alterations in the left ventricular wall, but none of them exhibited alterations in the septum.

The FAC was normal (between the 10th and the 75th percentiles) in most fetuses (73.01\%), and it increased in $26.99 \%$ of them. There were no cases with a FAC below the
Table 1 Epidemiological data on pregnant women with gestational diabetes mellitus*

\begin{tabular}{|l|l|c|}
\hline Maternal data & N & $\%$ \\
\hline \multicolumn{2}{|l|}{ Pregnant women's weight } & \multicolumn{2}{|l|}{} \\
\hline Normal & 22 & 34.92 \\
\hline High & 41 & 65.07 \\
\hline Total & 63 & 100.00 \\
\hline Parity & 21 & 33.33 \\
\hline Nulliparous & 42 & 66.66 \\
\hline Multiparous & 63 & 100.00 \\
\hline Total &
\end{tabular}

Note: *Absolute number (N) and percentage (\%).

10th percentile. Half of fetuses with normal abdominal circumferences exhibited HCM. The majority of the fetuses (64.7\%) with a FAC greater than the 75th percentile exhibited HCM. Fetal data are shown in - Table 2.

\section{Discussion}

Cardiomyopathies represent $8-11 \%$ of the cardiovascular abnormalities diagnosed during pregnancy. After birth, cardiomyopathies are diagnosed in only $3 \%$ of newborns with cardiovascular diseases, and diastolic dysfunction is associated with a higher risk of postnatal mortality. ${ }^{18}$

In a previous study that used septal and left ventricular wall thickness measures at birth as reference, it was reported that these values were increased in $69 \%$ of the fetuses of mothers with GDM; ${ }^{17}$ this value is slightly above the $\mathrm{CI}$

Table 2 Fetal data on interventricular septum, left ventricular wall, and abdominal circumference measurements*

\begin{tabular}{|c|c|c|}
\hline Fetal data & $N$ & $\%$ \\
\hline \multicolumn{3}{|l|}{ Interventricular septum } \\
\hline$<1 \mathrm{SD}$ & 7 & 11.1 \\
\hline SD between 1 and 2 & 24 & 38.0 \\
\hline$>2 \mathrm{SD}$ & 32 & 50.8 \\
\hline Total & 63 & 100.0 \\
\hline \multicolumn{3}{|l|}{ LV wall } \\
\hline$>2 \mathrm{SD}$ & 13 & 20.6 \\
\hline \multicolumn{3}{|l|}{ Fetal AC } \\
\hline Normal & 46 & 73.0 \\
\hline Increased & 17 & 27.0 \\
\hline Total & 63 & 100.0 \\
\hline
\end{tabular}

Abbreviations: AC, abdominal circumference; LV, left ventricular; SD, standard deviation.

Note: *Means and standard deviations, absolute numbers and percentages. 
obtained in our study. In the present study, we found that $54 \%$ (95\%CI: $41.3-65.1 \%$ ) of the fetuses evaluated before the treatment for GDM were positive for HCM.

Hypertrophic cardiomyopathy affects the right ventricle and the posterior left ventricular wall, but the septal hypertrophy is more evident because of the large number of insulin receptors in the septum of the heart. ${ }^{9,19,20}$ In our study, we observed that only 2 of the 34 fetuses with HCM exhibited alterations in the left ventricular wall, but none of them exhibited alterations in the septum.

The fetuses of mothers with GDM are at a risk of developing HCM even when the mothers exhibit good capillary glycemic control. ${ }^{16,21}$ Other authors have also not found a relationship between the glycemic control detected using maternal glycosylated hemoglobin and the presence of HCM. $^{22,23}$ These results show the limited existing knowledge about this disease.

Hyperinsulinemia is related to fetal macrosomia, and an increased FAC is directly related to higher fetal weight, and fetal weight is related to HCM. Moreover, the rate of HCM incidence in newborns that are large for their gestational age (LGA) can reach $38 \%{ }^{24}$ Considering that fetuses with FAC above the 75th percentile tend to be LGA, we found a higher percentage of $\mathrm{HCM}(64.7 \%)$ in these fetuses.

In our study, the fetuses were evaluated before initiating the treatment for GDM. Therefore, we do not know the effect of this treatment on HCM; a potential reduction would justify an incidence decline from $54 \%$ to $20 \%^{2}$ after delivery.

Hypertrophic cardiomyopathy was also observed in 50\% of the fetuses with normal FAC, which reflects the occurrence of interventricular septum alterations prior to FAC alterations. This result also suggests the diagnosis of poor maternal glycemic control even before FAC alterations.

Information on the postnatal consequences of HCM is insufficient in the current literature. ${ }^{21}$ There are evidences for the effects of diabetes on the cardiac function of adult patients. ${ }^{25}$ The abnormalities and injuries studied in adults are not easy to assess in fetuses because there is no evidence of the effects after the short period of exposure during pregnancy. ${ }^{26}$ Furthermore, a large majority of newborns is asymptomatic at birth, and if hypertrophy is present, it spontaneously regresses in a few months. ${ }^{18}$

Routine referral to fetal echocardiography for pregnant women with a history of diabetes mellitus has already been established according to some authors; ${ }^{24}$ the severity of the disease has also been established in this group. ${ }^{4}$ Some authors recommend that all pregnant women with GDM be submitted to fetal echocardiography until a group with a higher risk for HCM is identified. ${ }^{11}$

Because of the small sample size of the present study, several inferences could not be drawn from the results; however, the high prevalence and early occurrence of HCM in this population indicate that this is one of the first effects of maternal diabetes on fetuses. This observation justifies further assessments of this disease, including its onset, manifestations, behavior during maternal treatment, and the perinatal and adult repercussions.

\section{Conflicts of Interest}

The research was conducted at the Neonatology Centre of Maternidade Darcy Vargas, in Joinville, Santa Catarina, Brazil. Authors have no conflicts of interest to declare.

\section{References}

1 American Diabetes Association. Diagnosis and classification of diabetes mellitus. Diabetes Care 2012;35(Suppl 1):S64-S71

2 Åman J, Hansson U, Östlund I, Wall K, Persson B. Increased fat mass and cardiac septal hypertrophy in newborn infants of mothers with well-controlled diabetes during pregnancy. Neonatology 2011;100(02):147-154

3 Jaeggi ET, Fouron JC, Proulx F. Fetal cardiac performance in uncomplicated and well-controlled maternal type I diabetes. Ultrasound Obstet Gynecol 2001;17(04):311-315

4 Park MK. Pediatric cardiology. 4th ed. St. Louis: Mosby; 2002. Primary myocardial disease; p. 267-392

5 Demiroren K, Cam L, Oran B, et al. Echocardiographic measurements in infants of diabetic mothers and macrosomic infants of nondiabetic mothers. J Perinat Med 2005;33(03):232-235

6 Stuart A, Amer-Wåhlin I, Gudmundsson S, Marsál K, Thuring A, Källen K. Ductus venosus blood flow velocity waveform in diabetic pregnancies. Ultrasound Obstet Gynecol 2010;36(03): 344-349

7 Dimitriu AG, Russu G, Stamatin M, Jităreanu C, Streangă V. [Clinical and developmental aspects of cardiac involvement in infant of diabetic mother]. Rev Med Chir Soc Med Nat Iasi 2004; 108(03):566-569

8 Hagemann LL, Zielinsky P. [Prenatal study of hypertrophic cardiomyopathy and its association with insulin levels in fetuses of diabetic mothers]. Arq Bras Cardiol 1996;66(04):193-198

9 Fouda UM, Abou ElKassem MM, Hefny SM, Fouda RM, Hashem AT. Role of fetal echocardiography in the evaluation of structure and function of fetal heart in diabetic pregnancies. J Matern Fetal Neonatal Med 2013;26(06):571-575

10 García-Díaz L, Coserria F, Antiñolo G. Hypertrophic cardiomyopathy due to mitochondrial disease: prenatal diagnosis, management, and outcome. Case Rep Obstet Gynecol 2013;2013:472356

11 Zielinsky P. Role of prenatal echocardiography in the study of hypertrophic cardiomyopathy in the fetus. Echocardiography 1991;8(06):661-668

12 Hadlock FP, Deter RL, Harrist RB, Park SK. Estimating fetal age: computer-assisted analysis of multiple fetal growth parameters. Radiology 1984;152(02):497-501

13 Allan L. Technique of fetal echocardiography. Pediatr Cardiol 2004;25(03):223-233

14 Hendler I, Blackwell SC, Bujold E, et al. Suboptimal secondtrimester ultrasonographic visualization of the fetal heart in obese women: should we repeat the examination? J Ultrasound Med 2005;24(09):1205-1209, quiz 1210-1211

15 Lopes L. Ecocardiografia fetal. São Paulo: Revinter; 2015

16 Zielinsky P, Piccoli ALJr. Myocardial hypertrophy and dysfunction in maternal diabetes. Early Hum Dev 2012;88(05):273-278

17 Han SS, Wang G, Jin Y, et al. Investigating the mechanism of hyperglycemia-induced fetal cardiac hypertrophy. PLoS One 2015;10(09):e0139141

18 Pedra SR, Smallhorn JF, Ryan G, et al. Fetal cardiomyopathies: pathogenic mechanisms, hemodynamic findings, and clinical outcome. Circulation 2002;106(05):585-591

19 Garg S, Sharma P, Sharma D, Behera V, Durairaj M, Dhall A. Use of fetal echocardiography for characterization of fetal cardiac structure in women with normal pregnancies and gestational diabetes mellitus. J Ultrasound Med 2014;33(08):1365-1369

20 Otto CM. Fundamentos da ecocardiografia clínica. 3a ed. Rio de Janeiro: Elsevier; 2005. Cardiopatia hipertensiva e cor pulmonale; p. $199-220$ 
21 Garcia-Flores J, Jañez M, Gonzalez MC, Martinez N, Espada M, Gonzalez A. Fetal myocardial morphological and functional changes associated with well-controlled gestational diabetes. Eur J Obstet Gynecol Reprod Biol 2011;154(01):24-26

22 Vela-Huerta MM, Vargas-Origel A, Olvera-López A. Asymmetrical septal hypertrophy in newborn infants of diabetic mothers. Am J Perinatol 2000;17(02):89-94

23 Behle I, Zielinsky P, Zimmer LP, Pontremoli M, Risch JN. [Glycosylated hemoglobin levels and cardiac abnormalities in fetuses of diabetic mothers]. Rev Bras Ginecol Obstet 1998;20(05):237-243 Portuguese.
24 Vural M, Leke L, Mahomedaly H, Maingourd Y, Kremp O, Risbourg B. Should an echocardiographic scan be done routinely for infants of diabetic mothers? Turk J Pediatr 1995;37(04): 351-356

25 Fonarow GC. Managing the patient with diabetes mellitus and heart failure: issues and considerations. Am J Med 2004;116(Suppl A) $76 \mathrm{~S}-88 \mathrm{~S}$

26 Figueroa H, Silva MC, Kottmann C, et al. Fetal evaluation of the modified-myocardial performance index in pregnancies complicated by diabetes. Prenat Diagn 2012;32(10):943-948 